\title{
Material characterization of polyamide 12 and related agents used in the multi-jet fusion process: complementary application of high-resolution mass spectrometry and other advanced instrumental techniques
}

\author{
Beate Scherer $^{1,2} \cdot$ Ingo Leonard Kottenstedde ${ }^{1,3} \cdot$ Frank-Michael Matysik $^{2}$
}

Received: 11 March 2020 / Accepted: 16 June 2020 / Published online: 24 July 2020

(c) The Author(s) 2020

\begin{abstract}
The powder bed-based 3D printing process called multi-jet fusion from HP is used in various industries for different applications. A polymer powder, the so-called fusing and detailing agents, and an IR source are needed. These novel materials offer some challenges for analytical characterization. High-resolution mass spectrometry in combination with a data base search was used as a tool for comprehensive characterization of the agents, the methanol extract of new polyamide 12 powder, and the methanol extract of a grinded 3D printed part. In addition, thermogravimetric studies were carried out. Besides biocides and substances containing ethoxy units, 2-pyrrolidone and triethylene glycol were identified as organic solvents in the agents. The detailing agent contained $3.7 \%$ of 2-pyrrolidone and $11.1 \%$ of triethylene glycol. The fusing agent contained $18.7 \%$ of 2-pyrrolidone and $8.4 \%$ of triethylene glycol. Based on the agents' different functionalities, the water content of the detailing agent was $18 \%$ higher as compared to the fusing agent. In addition, the fusing agent contained a carbon black amount of $5.2 \%$. The methanol extract of new polyamide 12 powder contained remaining monomer and oligomer compounds, as well as the oxidation stabilizer Irganox 1098. In the methanol extract of the grinded 3D printed part the cyclic and linear monomer, oligomers, and oxidation stabilizer were found. Moreover, ingredients of the agents were detected. Residues of 2-pyrrolidone, triethylene glycol, 3-benzisothiazolinone, and substances containing ethoxy units were identified in the methanol extract of the grinded 3D printed part. In contrast, no 2-methyl-4-isothiazolin-3-one was observed.
\end{abstract}

\section{Graphical abstract}

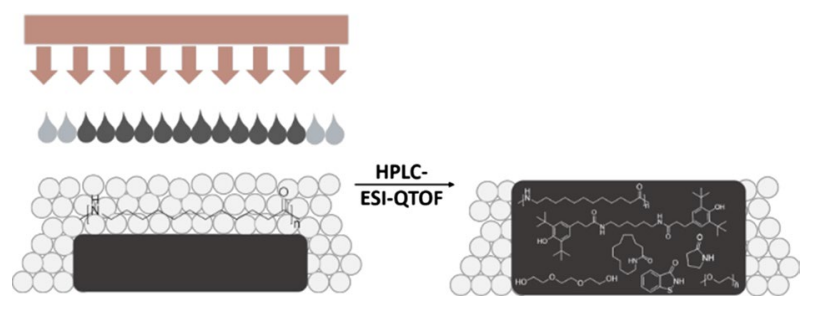

Keywords High-pressure liquid chromatography $\cdot$ Mass spectrometry $\cdot$ Oligomers $\cdot$ Material science $\cdot$ Multi-jet fusion . Additive manufacturing

Frank-Michael Matysik

Frank-Michael.Matysik@chemie.uni-regensburg.de

BMW AG, 84122 Dingolfing, Germany

2 Department of Chemistry and Pharmacy, University of Regensburg, 93040 Regensburg, Germany

3 Department of Chemistry, University of Paderborn, 33098 Paderborn, Germany

\section{Introduction}

The importance of additive manufacturing is increasing, involving applications in automotive, aerospace, and medical industry [1]. Over the years, several different technologies have been developed to satisfy the needs of the various 
application areas. Powder-based techniques are categorized as being among the most important ones in additive manufacturing [2]. As one of the advantages powder is only fused in positions where needed and the remaining powder can be recycled.

In 2016, the new technology named multi-jet fusion was commercially introduced by the company HP [3, 4]. A simplified process chain is shown in Fig. 1. The process starts with a controlled deposition of a thin layer of pre-heated powder particles, whereby the thickness of one layer is $80 \mu \mathrm{m}$ [5]. Then, a combination of agents is applied by printheads. First, a black fusing agent is distributed selectively on the polymer surface where the powder is determined to coalesce. In a second step, the detailing agent is deposited on the adjacent bulk powder. The detailing agent improves the accuracy and surface quality of the printed parts by absorbing heat due to its high water content [4]. IR radiation is applied to the powder bed by means of an IR lamp that is moved across the powder surface. It melts the powder material, which is covered with fusing agent as solely the fusing agent is able to absorb IR radiation. These steps are repeated layer by layer until the printing process is completed [3, 6].

Besides HP 3D High Reusability Polyamide 12 (HP PA 12), available powder materials are polyamide 12 (PA 12) filled with glass beads, and polyamide 11 (PA 11), whereby the focus on this study is on HP PA 12 [6]. PA 11 and PA 12 both offer good properties regarding $3 \mathrm{D}$ printing and are commonly used in powder bed fusion processes [3]. PA 12 is synthesized by ring opening polyaddition between azacyclotridecan-2-one (laurolactam) and water [7]. The recyclability and reusability of the polymer powder are considered as a key point for the industrialization of multi-jet fusion and selective laser sintering. Changing properties of the material during the printing process may affect processing and thus the reusability of the polymer [2].

In general, polyamides (PAs) are sensitive to oxygen and deterioration of properties, resulting in yellowing and embrittlement likely to occur due to oxidation. Corresponding studies found that the oxidation of PAs is proceeded by a free-radical chain reaction $[8,9]$. Consequently, different types of stabilizers in low concentration are added to the polymer material in order to protect the polymer itself against temperature, light, and oxygen. Phenols are most often used as antioxidants, followed by phosphites and sulfur compounds. The choice of stabilizers for PAs primarily depends on the processing temperatures of the materials and the decomposition temperatures of the stabilizers [10]. Copper salts in combination with halogen or phosphorous compounds are efficient at temperatures higher than $140{ }^{\circ} \mathrm{C}$. However, the mechanism of the copper stabilization is not fully understood. It is assumed that a redox reaction interferes with the radical chain reaction $[10,11]$. Aromatic amines show a stabilizing effect up to $140{ }^{\circ} \mathrm{C}$ whereby a color change may occur. Furthermore, they are of toxicological concern. Phosphites are applied as co-stabilizers for phenolic oxidation stabilizers and show synergistic effects [10, 12]. Sterically hindered phenols act as radical scavengers resulting in the use of compounds such as different Irganox types $[13,14]$.

Besides molecules added for stabilization, residues of monomers and oligomers, too, can be found in the polymer as equilibrium products of the polymerization process. However, in literature, the analysis of cyclic oligomers of $\varepsilon$-caprolactam is most often quoted [15]. Mengerink et al. [16] determined cyclic and linear polyamide 6 (PA 6) oligomers by gradient elution chromatography, whereby formic acid was used as a modifier on a reversed phase. The majority of the condensation products was linear but cyclic structures were detected in the low-molecular mass region as well. Linear oligomers were determined in the range of the hexamer up to the tetracontamer [16]. Another study investigated cyclic and linear monomers and oligomers in PA 6, PA 66, and PA 12. In total, $1.5 \%$ cyclic oligomers in PA 12 as compared to $10.1 \%$ in PA 6 were observed [17]. Moreover, the formation of cyclic monomers and oligomers depends on the thermodynamic stability of the ring and the distance of the end groups which have to react with each other. Consequently, the amount of monomers and oligomers is much lower in case of PA 12 compared to PA 6 [18].

Väisänen et al. [19] investigated the multi-jet fusion process regarding gaseous and particulate contaminants. In their studies pyrrolidin-2-one (2-pyrrolidone) $\left(549-564 \mu \mathrm{g} \mathrm{m}^{-3}\right)$ a

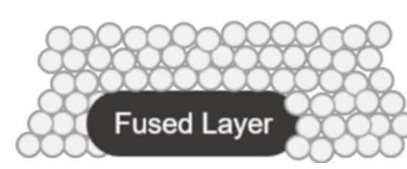

b
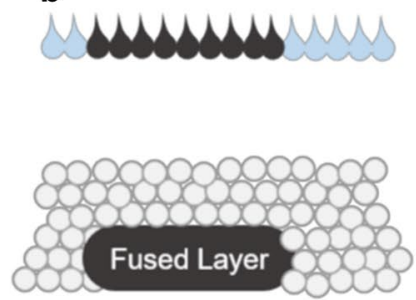

c
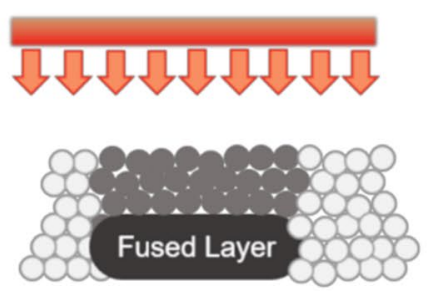

d



Fig. 1 Scheme of the multi-jet fusion process. a applied layer of polymer powder, b application of the agents (black: fusing agent, light blue: detailing agent), $\mathbf{c}$ energy delivery by IR radiation, and $\mathbf{d}$ fused layer [6] (color figure online) 
and 2-[2-(2-hydroxyethoxy)ethoxy]ethanol (triethylene glycol) $\left(201-211 \mathrm{\mu g} \mathrm{m}^{-3}\right)$ were found besides acetone, formaldehyde, and butan-2-one which were detected in concentrations ranging from $14 \mu \mathrm{g} \mathrm{m}^{-3}$ up to $41 \mu \mathrm{g} \mathrm{m}^{-3}$ [19].

So far, in the literature, little information about the analytical characterization of the agents applied in multi-jet fusion process is reported. The scope of this work was to investigate the agents and the methanol extracts of new HP PA 12 powder and a grinded 3D printed part, as all of these materials are important for the quality control of the multi-jet fusion process. The investigation of these materials is associated with various analytical challenges. First characterization was achieved by means of high-performance liquid chromatography (HPLC) in combination with highresolution time-of-flight mass spectrometry. As the agents are used as processing aids, remaining components might still be present in printed parts and influence the properties of the final product. Therefore, the present work aimed to identify and to determine ingredients of the agents in real samples of printed parts.

\section{Results and discussion}

\section{Qualitative investigations of detailing and fusing agents}

For qualitative investigations of the agents HPLC in combination with positive electrospray ionization-quadrupole-time-of-flight (HPLC-ESI-QTOF) experiments were conducted.

The total-ion chromatograms (TICs) of both agents are illustrated in Fig. 2a, b. In the retention time window up to $2.5 \mathrm{~min}$, the shape of the TIC traces looked similar. After $2.5 \mathrm{~min}$, however, the chromatograms differed from each other. The first peak $(1.1 \mathrm{~min})$ was integrated for both agents and two mass traces occurring in both agents were identified. The application of Agilents' library for extractables and leachables and the characteristic isotopic pattern helped to identity 2-pyrrolidone and triethylene glycol as organic solvents in both agents. The calculated $[\mathrm{M}+\mathrm{H}]^{+}$values of
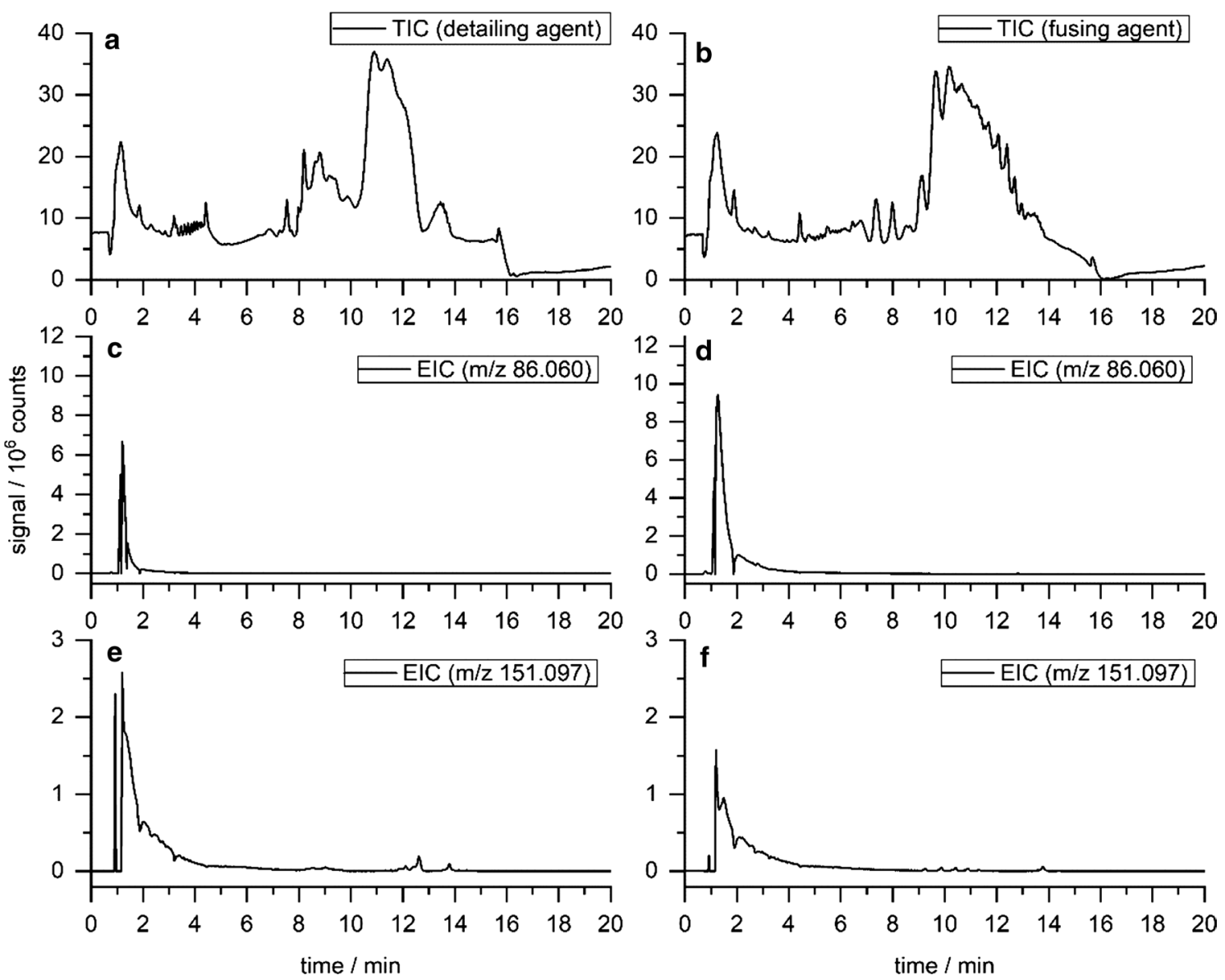

Fig. 2 a, b Total-ion chromatograms (TICs) of detailing and fusing agents. Extracted ion chromatograms (EICs) of $m / z 86.060\left([\mathrm{M}+\mathrm{H}]^{+}\right.$ of 2-pyrrolidone) contained in detailing (c) and fusing (d) agents.

EIC traces of $m / z, 151.097\left([\mathrm{M}+\mathrm{H}]^{+}\right.$of triethylene glycol) detected in both agents $(\mathbf{e}, \mathbf{f})$. The chromatograms $\mathbf{c}-\mathbf{f}$ were extracted with a mass range interval of $\pm 20 \mathrm{ppm}$ from the TIC traces above, respectively 
both substances (2-pyrrolidone: $\mathrm{m} / \mathrm{z} 86.060$, triethylene glycol: $m / z, 151.097$ ) were extracted from the TIC with a mass range interval of $\pm 20 \mathrm{ppm}$. The corresponding extracted ion chromatograms (EICs) for detailing and fusing agents are shown in Fig. 2c-f. The intensities of the EIC curves differed for both substances and agents. The positive mode of ESI was chosen as it offered better response compared to the negative mode. Besides the extraction solvent methanol, acetonitrile/tetrahydrofuran $(9: 1, \mathrm{v} / \mathrm{v})$ was tested as well, but led to a lower number of signals. Consequently, methanol was chosen as the extraction solvent for all experiments.

One reason for including 2-pyrrolidone in the formulations of the agents could be the high boiling point of $251{ }^{\circ} \mathrm{C}$, resulting in a low tendency for outgassing [20]. In addition, triethylene glycol is a water soluble and colorless additive with low volatility and a very high boiling point $\left(288^{\circ} \mathrm{C}\right)$. Furthermore, the application of triethylene glycol in printing inks, cleaning compounds, and heat-transfer fluids is reported in the literature [21].

The detailing agent contained 3.7\% of 2-pyrrolidone and $11.1 \%$ triethylene glycol, quantified by gas chromatography-flame ionization detection (GC-FID). The fusing agent contained $18.7 \%$ of 2-pyrrolidone and $8.4 \%$ of triethylene glycol. Besides organic solvents, the fusing and detailing agents included a certain amount of water. The water content of the agent was measured by Karl Fisher titration and was determined as $83 \%$ in detailing agent and $65 \%$ in fusing agent. The high water content of the detailing agent has a local cooling effect based on the evaporation energy being removed. Consequently, during the printing process contours become sharper and the surface quality is increased. In addition, detailing agent can be applied on the same area as the fusing agent to establish a better heat control [4]. The water content of the fusing agent is lower since its aim is to obtain proper IR absorption resulting in coalescing polymer. In addition, the aqueous nature of the fusing agent permits partial penetration into the layer of the powder material. For a homogeneous distribution of carbon black in the liquid, surfactants and organic co-solvents are required. These ingredients provide a desirable wetting behavior [22, 23].

Besides the main components, it was more difficult to identify the ingredients with lower content. In Fig. 3c, d, $\mathrm{g}, \mathrm{h}$, the EIC of 2-methyl-1,2-thiazol-3-one (2-methyl4-isothiazolin-3-one) and 1,2-benzothiazol-3-one (3-benzisothiazolinone) both extracted from the TIC traces of the agents, respectively, are depicted. These types of biocides are UV-active based on their molecular structure including a conjugated $\pi$-electron system. The UV activity of 2-methyl4-isothiazolin-3-one was confirmed by the corresponding UV signal at a wavelength of $280 \mathrm{~nm}$ (see Fig. 3e, f). The UV signal of 3-benzisothiazolinone at a wavelength of $250 \mathrm{~nm}$ is depicted in Fig. 3i, j. The fusing agent showed lower intensities of 2-methyl-4-isothiazolin-3-one and 3-benzisothiazolinone. These biocides are added to the agents to prevent biocidal contaminations and bacterial growth during storage and the period of use. Thus, the water content of the agents is probably in direct correlation with biocide concentration. In [24], it is reported that halogenfree isothiazolinones were used in combination of two or more isothiazolinones in order to ensure storage stability over time and at increased temperatures. The safety data sheets of the agents declare that biocides are included in a quantity of $<0.1 \%$ in the agents. Furthermore, 2-pyrrolidone and carbon black have to be listed, respectively [25, 26].

The identification of molecules containing ethoxy units in detailing agent is illustrated in Figs. 4 and 5. In Fig. 4a-d, average mass spectra of the peak area from 3.1 to $4.6 \mathrm{~min}$ of the TIC of detailing agent at different collision energies are depicted, i.e. mass spectra with the following collision energies: $0 \mathrm{eV}$ (a), $20 \mathrm{eV}$ (b), $30 \mathrm{eV}$ (c), and $40 \mathrm{eV}$ (d). As Fig. 4a depicts the MS spectrum without collision energy, a homogeneous distribution of $\mathrm{m} / \mathrm{z}$ signals in the range of $\mathrm{m} / \mathrm{z} 380$ up to almost $\mathrm{m} / \mathrm{z} 900$ is recognizable. In Fig. $4 \mathrm{~b}$ the MS spectrum with $20 \mathrm{eV}$ collision energy is shown. Consequently, the intensity of mass traces in the range of $\mathrm{m} / \mathrm{z} 380$ up to $\mathrm{m} / \mathrm{z} 900$ became smaller, resulting in peaks that were hardly visible at collision energies of $30 \mathrm{eV}$ and $40 \mathrm{eV}$ (compare Fig. 4c, d). Instead, the intensity of fragmentation products increased resulting in peaks appearing in the range of $\mathrm{m} / \mathrm{z} 80$ up to $\mathrm{m} / \mathrm{z} 150$. The mass trace $\mathrm{m} / \mathrm{z}$ 177.11 arose at a collision energy of $20 \mathrm{eV}$, but the intensity decreased at a collision energy of $30 \mathrm{eV}$ and disappeared at the collision energy of $40 \mathrm{eV}$. Moreover, the intensity of the mass trace $m / z 133.08$ decreased for a collision energy of $40 \mathrm{eV}$ to about half of its value at $30 \mathrm{eV}$.

Figure $5 \mathrm{a}, \mathrm{b}$ provides more detailed information about the average mass spectra of the peak area from 3.1 to $4.6 \mathrm{~min}$ without collision (a) and with a collision energy of $20 \mathrm{eV}$ (b). The average MS spectrum without collision energy shows a difference of $44.03 \mathrm{~g} \mathrm{~mol}^{-1}$ of the signals in the range of $\mathrm{m} / \mathrm{z} 380$ up to $\mathrm{m} / \mathrm{z} 900$, which is an indicator for ethoxy units. The assumption of molecules in the detailing agent which include ethoxy units was confirmed by the MS spectrum with a collision energy of $20 \mathrm{eV}$. High intensities of $\mathrm{m} / \mathrm{z} 89.06$ and $\mathrm{m} / \mathrm{z} 133.08$ can be seen in Fig. $5 \mathrm{~b}$. Those two $\mathrm{m} / \mathrm{z}$ values equal the chemical formulas of $2\left(\left[\mathrm{C}_{4} \mathrm{H}_{8} \mathrm{O}_{2}+\mathrm{H}\right]^{+}\right)$and $3\left(\left[\mathrm{C}_{6} \mathrm{H}_{12} \mathrm{O}_{3}+\mathrm{H}\right]^{+}\right)$ethoxy units and confirm the assumption of compounds containing ethoxy units in detailing agent. The calculated corresponding masses were $\mathrm{m} / \mathrm{z} 89.059$ and $\mathrm{m} / \mathrm{z}, 133.086$ for two and three protonated ethoxy units. The ethoxy units could be part of polyethylene glycols (PEG) which usually show a distinct molar mass distribution (see Fig. 5a). Comparing the distribution curves of the higher $\mathrm{m} / \mathrm{z}$ values of Fig. $5 \mathrm{a}$ and $5 \mathrm{~b}$, a change of the local maxima in the range of $m / z 380$ to $\mathrm{m} / \mathrm{z} 900$ from around $\mathrm{m} / \mathrm{z} 600$ to $\mathrm{m} / \mathrm{z} 750$ could be observed. 


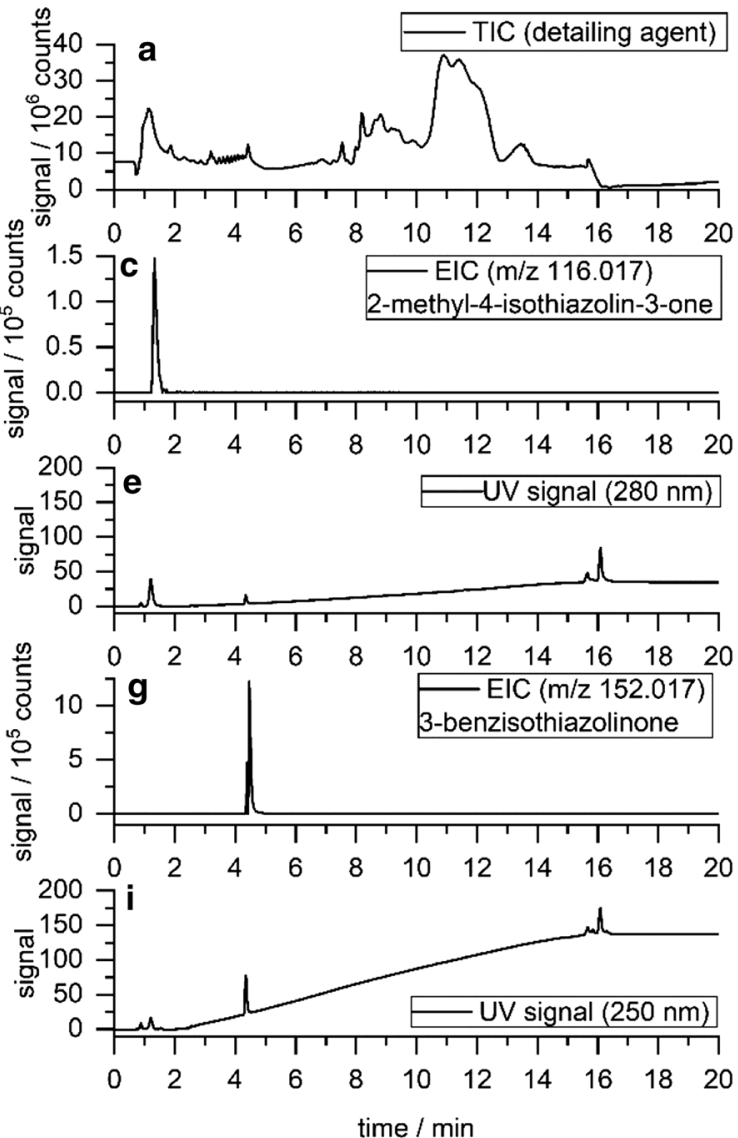

Fig. 3 a, b TIC traces of detailing and fusing agents. EIC traces of 2-methyl-4-isothiazolin-3-one $(\mathrm{m} / \mathrm{z}, 116.017)$ contained in detailing (c) and fusing (d) agents. EIC of 3-benzisothiazolinone $(\mathrm{m} / \mathrm{z}$ 152.017) detected in both agents $(\mathbf{g}, \mathbf{h})$. In $\mathbf{e}, \mathbf{f}, \mathbf{i}$, and $\mathbf{j}$ UV signals at a wave-

As non-ionic surfactants PEGs help to ensure homogenous solutions between water, organic solvents, and further additives. Moreover, they can be used to adjust the viscosity of the detailing agent.

Figure 6a-d shows the EIC traces of $m / z 89.060$ and $\mathrm{m} / \mathrm{z}, 133.086$ extracted out of all scans with different collision energies for fusing and detailing agents. Thus, the intensities of the mass traces obtained from experiments with different collision energies $(0 \mathrm{eV}, 20 \mathrm{eV}, 30 \mathrm{eV}$, and $40 \mathrm{eV}$ ) were added, respectively. Consequently, the higher intensities were caused by molecules including a larger number of ethoxy units. Moreover, it becomes obvious that compounds with 2 and 3 ethoxy units were included in both agents and distributed over the complete chromatograms. The EIC traces of $m / z 89.060$ and 133.086 of detailing and fusing agents varied slightly. Furthermore, the intensity in the detailing agent was higher as compared to the fusing agent. Additionally, the distribution of the curves of detailing and fusing agents differed. Comparing the EIC traces of detailing and fusing agents, the chromatograms showed that the signals in the retention time window from 3 to $9.5 \mathrm{~min}$
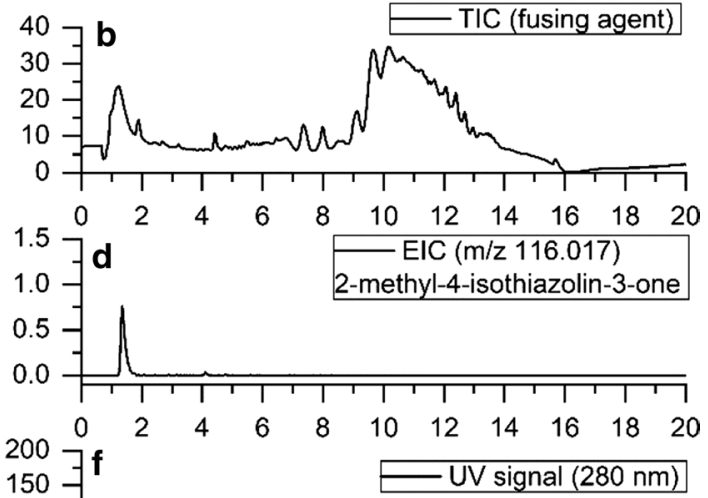

$150-$

$100-$

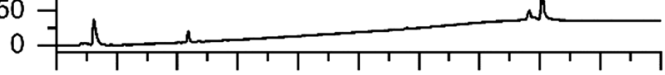

$\begin{array}{lllllllllll}0 & 2 & 4 & 6 & 8 & 10 & 12 & 14 & 16 & 18 & 20\end{array}$
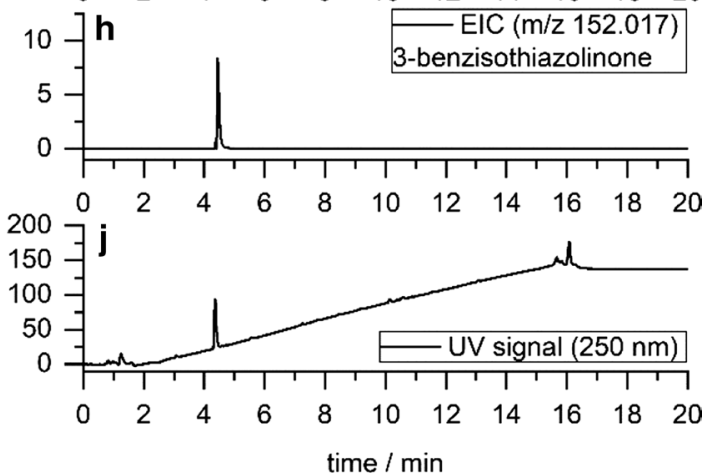

length of $280 \mathrm{~nm}$ and $250 \mathrm{~nm}$ are depicted and confirm the biocidal compounds. The EIC traces were extracted with a mass range interval of $\pm 100 \mathrm{ppm}$

appearing in detailing agent are missing in the EIC curves of fusing agent. This was one indicator that the composition of those agents varied regarding their compounds with ethoxy units which could, e.g. be different molar mass distributions of polyethylene glycols or non-ionic surfactants differing in their functional groups. However, based on Fig. 6, it was not possible to draw a conclusion regarding the distinct compounds containing the ethoxy units. Therefore, a closer evaluation of mass distribution in dependence of the retention time would be necessary.

All of the detected compounds in this section are included in fusing and detailing agents, but by having a closer look at the chromatograms and mass spectra, differences in the chromatograms themselves and in the intensities of the EIC traces could be seen.

By applying thermogravimetric analysis (TGA), the amount of carbon black in both agents could be investigated. Therefore, mass losses at different temperatures and gas atmospheres led to information on the material composition of the agents. The corresponding measurement curves are shown in Fig. 7. The samples were conditioned before the 

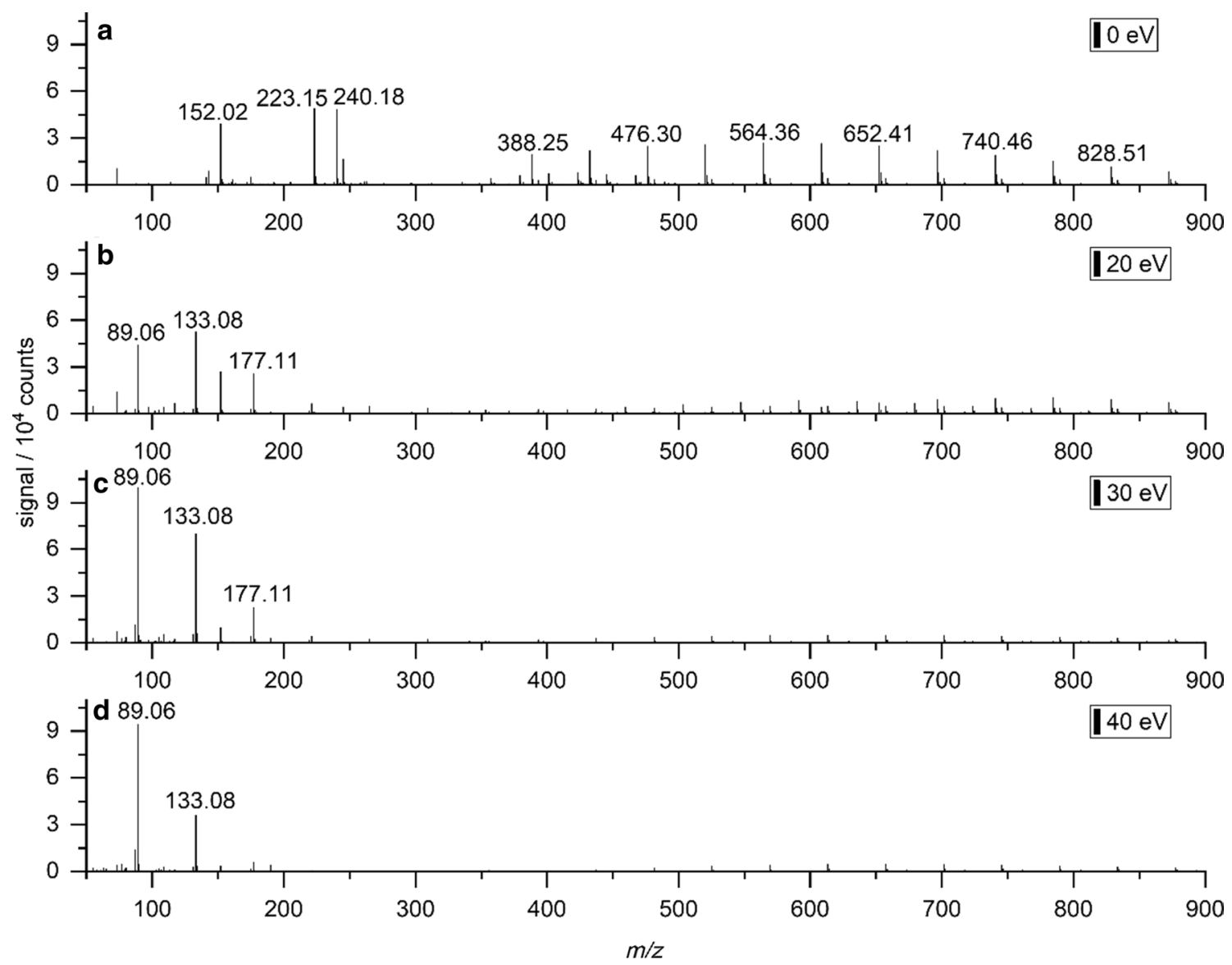

Fig. 4 a-d Average mass spectra of the peak area from 3.1-4.6 min of the TIC of detailing agent at different collision energies. Collision energies a $0 \mathrm{eV}$; b $20 \mathrm{eV}$; $30 \mathrm{eV} ; \mathbf{d} 40 \mathrm{eV}$

measurements. Preliminary mass losses of $82.2 \%$ and $61.5 \%$ for detailing and fusing agents were found. In the following, we discuss the TGA results of conditioned samples in detail. At first, an isothermal segment at $28^{\circ} \mathrm{C}$ in nitrogen atmosphere allowed to detect the amount of adsorbed moisture contained in the samples. Water molecules were desorbed by convection resulting in a slight mass loss of $2.4 \%$ and $2.5 \%$ for detailing and fusing agent, respectively. The following heating phase to $800{ }^{\circ} \mathrm{C}$ at $10 \mathrm{~K} \mathrm{~min}^{-1}$ showed a two-step thermal degradation of the ingredients triethylene glycol, 2-pyrrolidone, and other additives of higher thermal resistance for both samples in the range of $100-450{ }^{\circ} \mathrm{C}$. The next heating phase from 800 to $950{ }^{\circ} \mathrm{C}$ at $10 \mathrm{~K} \mathrm{~min}^{-1}$ took place in a pure oxygen atmosphere. Carbon black or pyrolysis products were oxidized by oxygen in this temperature segment. Clear differences between the samples could be observed. The detailing agent showed no mass loss under oxygen atmosphere. All components were already evaporated or completely decomposed without the formation of char by pyrolysis. However, a mass loss of $13.6 \%$ was detected in the fusing agent. This was due to the amount of carbon black present in the formulation. By taking the mass loss of the conditioning step into consideration, the amount of carbon black was calculated as $5.2 \%$.

\section{Qualitative investigations of HP PA 12 powder}

Besides the agents, the methanol extract of the new HP PA 12 powder was investigated. The corresponding TIC curve is depicted in Fig. 8a. An overview of detected monomers and oligomers together with the molecular structures is shown in Fig. 8b-k.

The calculated masses of the cyclic (b) and the linear (e) dimer were extracted as $[\mathrm{M}+\mathrm{H}]^{+}$which equals $\mathrm{m} / \mathrm{z}$ values of 395.363 and 413.374, respectively. However, within the EIC of the cyclic dimer (b) more peaks were detected in the EIC starting with the first peak at the retention time of the linear dimer. Thus, the linear dimer could also form the cyclic dimer during the ionization process in the ESI spray chamber. In this case, more complicated situations of other species may contribute. In Fig. 8c the EIC of the cyclic PA 12 monomer laurolactam is depicted. Thus, residues of the laurolactam could be found in intensities of up to $5 \times 10^{6}$ counts. Moreover, the linear monomer and other oligomers 


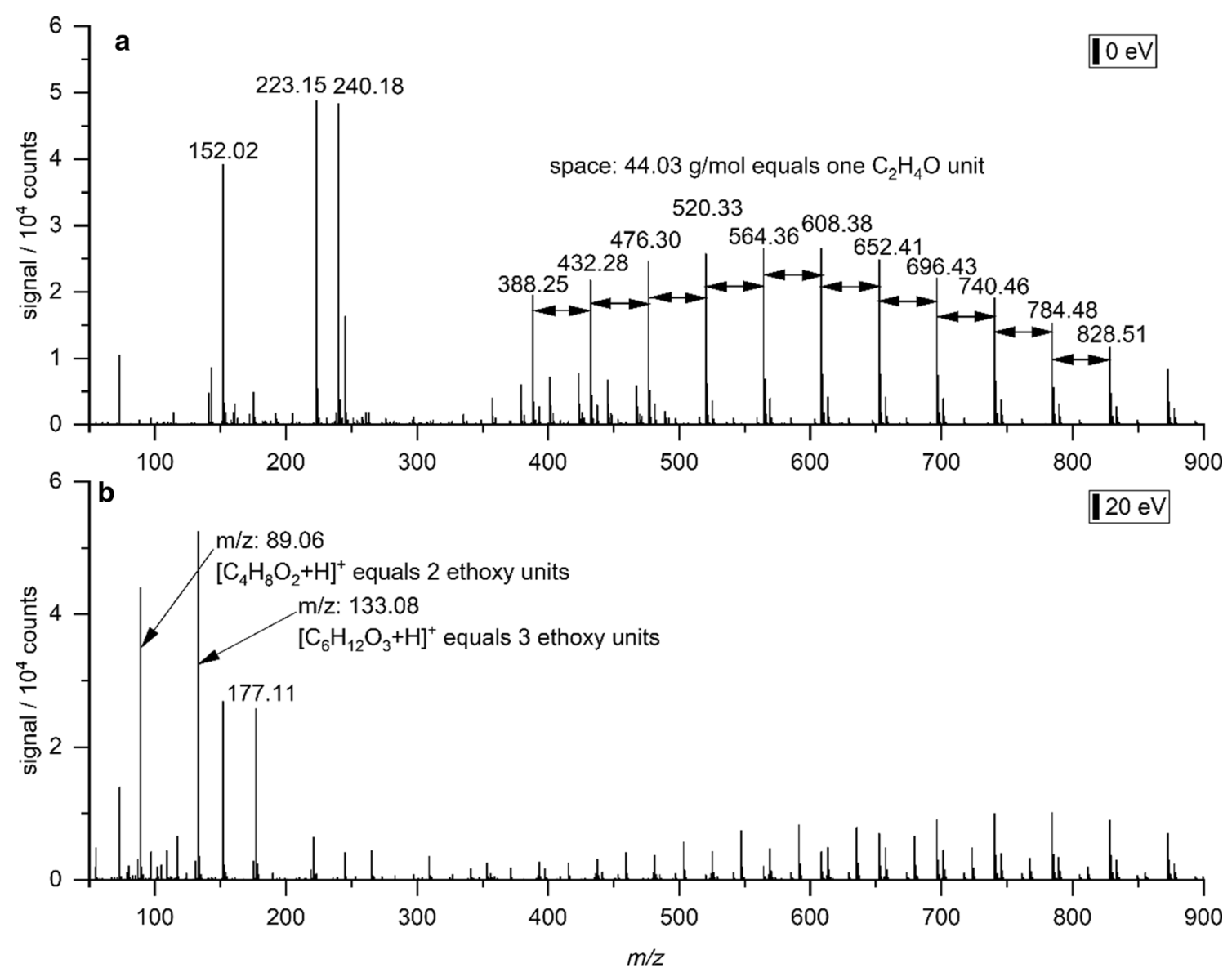

Fig. 5 Identification of compounds containing ethoxy units in detailing agent. Average mass spectra of the peak area from 3.1-4.6 min (a) without collision and (b) with a collision energy of $20 \mathrm{eV}$

are also side products of the polymerization process. Figure $8 \mathrm{~g}$ shows one single peak of the cyclic trimer with an intensity of $4 \times 10^{6}$ counts which is in the range of the intensities of the cyclic dimer and monomer. In Fig. $8 \mathrm{f}$ the EIC of the identified oxidation stabilizer Irganox 1098 is depicted. Its identity could be proven by comparison of the UV-spectra and the retention time of a reference standard. Okamba et al. [13] investigated three phenol stabilizers in PA 11. These were $N, N^{\prime}$-1,6-hexanediylbis[3,5-bis(1,1-dimethylethyl)-4hydroxyphenylpropanamide (Irganox 1098), [3-[3-(3,5-ditert-butyl-4-hydroxyphenyl)propanoyloxy]-2,2-bis[3-(3,5di-tert-butyl-4-hydroxyphenyl)propanoyloxymethyl] propyl] 3-(3,5-di-tert-butyl-4-hydroxyphenyl)propanoate (Irganox 1010), and 2-[2-[2-[3-(3-tert-butyl-4-hydroxy5 -methylphenyl)propanoyloxy] ethoxy] ethoxy] ethyl 3-(3-tert-butyl-4-hydroxy-5-methylphenyl)propanoate (Irganox 245), whereby Irganox 1098 is commonly used for the stabilization of PAs [27]. In general, for the application of stabilizers in PA 12 in the multi-jet fusion process, the stabilizer needs to be applicable for the polymer itself. Furthermore, the stabilizer has to withstand high temperatures during the printing process and therefore Irganox 1098 offers good thermal long-term stability [9]. The linear monomer 12-aminolauric acid (compare Fig. 8g, RT 5.9 min) eluted earlier from the column as compared to the cyclic monomer (RT $7.9 \mathrm{~min}$ ) due to higher polarity. The linear oligomers tended to elute earlier compared to the cyclic ones, which is caused by the higher hydrophilicity of the linear forms. Figure 8k shows the linear PA 12 pentamer, whereby the cyclic pentamer could not be detected anymore. A decreasing intensity of the higher oligomers was observed. However, the cyclic oligomers always showed higher intensities compared to the corresponding linear oligomers, whereby the highest intensities were observed within the peak of the cyclic dimer (b). A closer look at the retention times, however, shows that the current HPLC method was not able to separate all of the monomers and oligomers from each other. Laurolactam showed a partial coelution with the linear dimer. Furthermore, a limited resolution of Irganox 1098, the cyclic tetramer, and the linear pentamer could be noticed as all of these substances eluted at retention times around $12 \mathrm{~min}$. Moreover, the cyclic trimer coeluted with the linear 

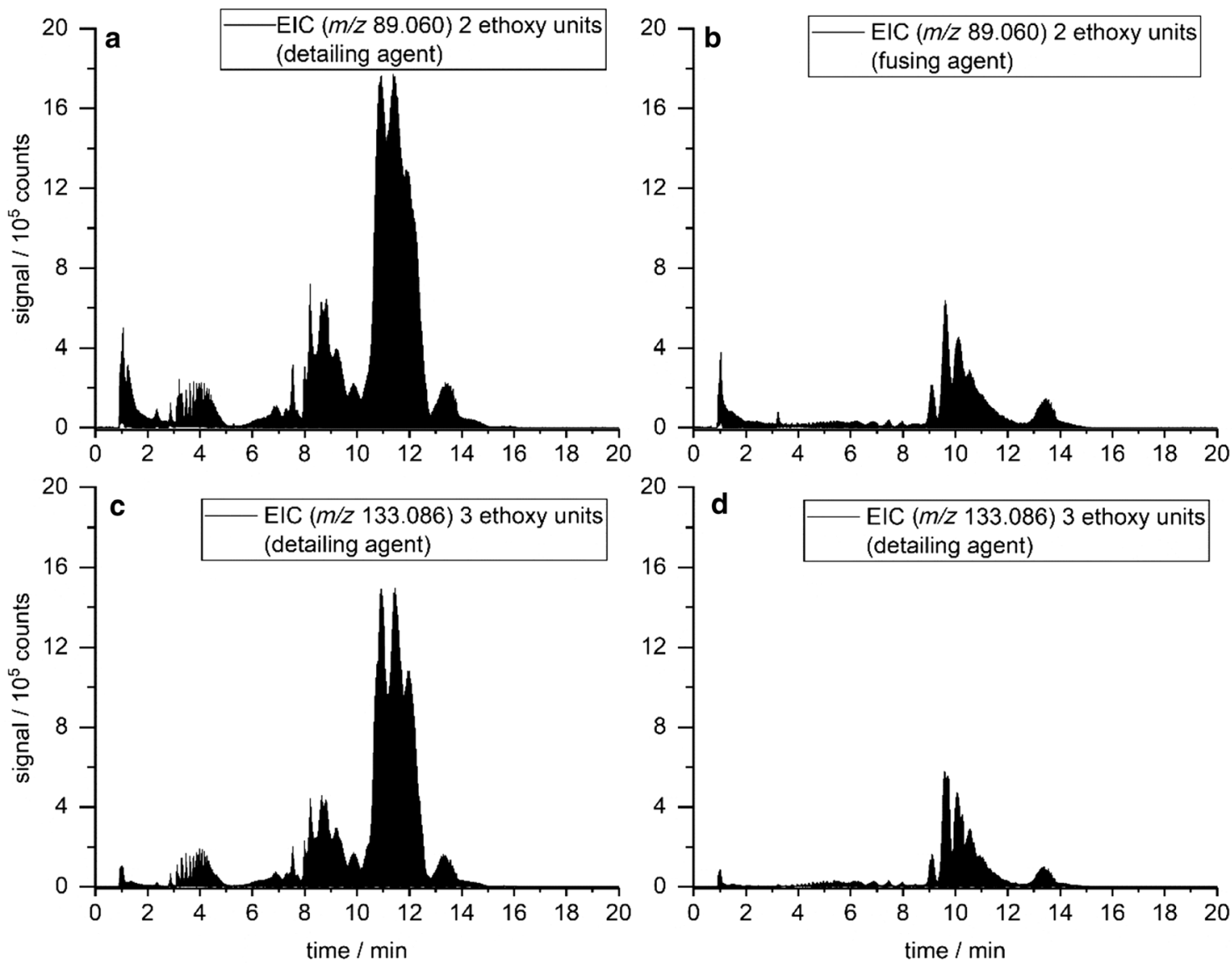

Fig. 6 a-d EICs of $\mathrm{m} / \mathrm{z} 89.060$ (equals 2 ethoxy units) and $\mathrm{m} / z 133.086$ (equals 3 ethoxy units) of detailing and fusing agents. The intensities of the mass traces obtained at different collision ener-

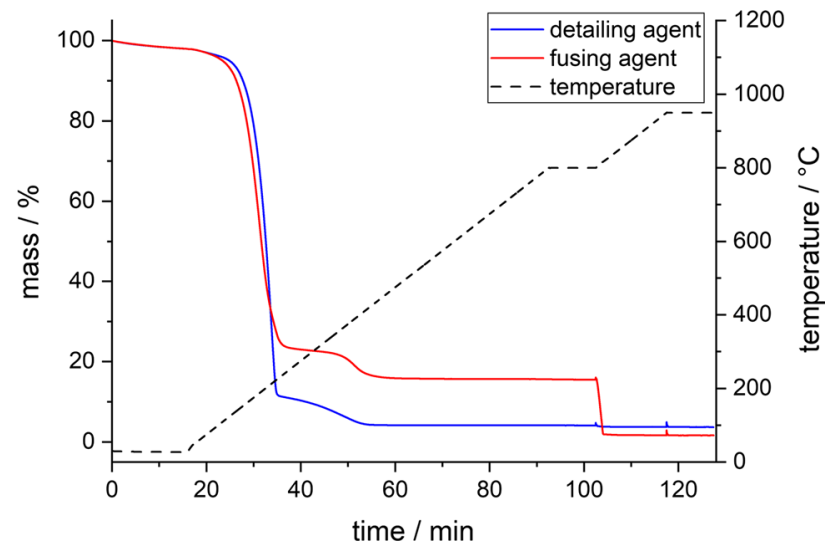

Fig. 7 Thermogravimetric measurements of detailing and fusing agents as a function of time in reference to the temperature profile (color figure online)

tetramer at 11.3 min and the cyclic dimer with the linear trimer at $10 \mathrm{~min}$. Further method development would be necessary to achieve a complete separation by reversed-phase gies $(0 \mathrm{eV}, 20 \mathrm{eV}, 30 \mathrm{eV}$, and $40 \mathrm{eV})$ were summed up. The chromatograms were extracted with a mass range interval of $\pm 100 \mathrm{ppm}$

HPLC. For the investigation of higher oligomers other detection principles, such as evaporative light scattering detection or charged aerosol detection in combination with gradient elution chromatography, could be helpful [16].

\section{Investigations of printed parts}

Besides the pure agents and the methanol extract of a new polymer powder, the methanol extract of a printed part was investigated in order to obtain information on whether residues of the agents could be detected in the printed part. The TIC of a HP PA 12 new powder sample extracted with methanol (red line) and an overlay with the TIC of a methanol extract of a printed part (blue line) is shown in Fig. 9. Differences in the TIC traces can be seen. Higher intensities in the retention time window (0.7-1.5 $\mathrm{min}$ ) were obtained concerning the HP PA 12 component. Additionally, the peak pattern in the range of 1.7-4.5 min showed similarities with the TIC recording of detailing agent in the same retention time window, which was interpreted as a first indicator for parts of the detailing agent remaining in the printed part. Furthermore, 

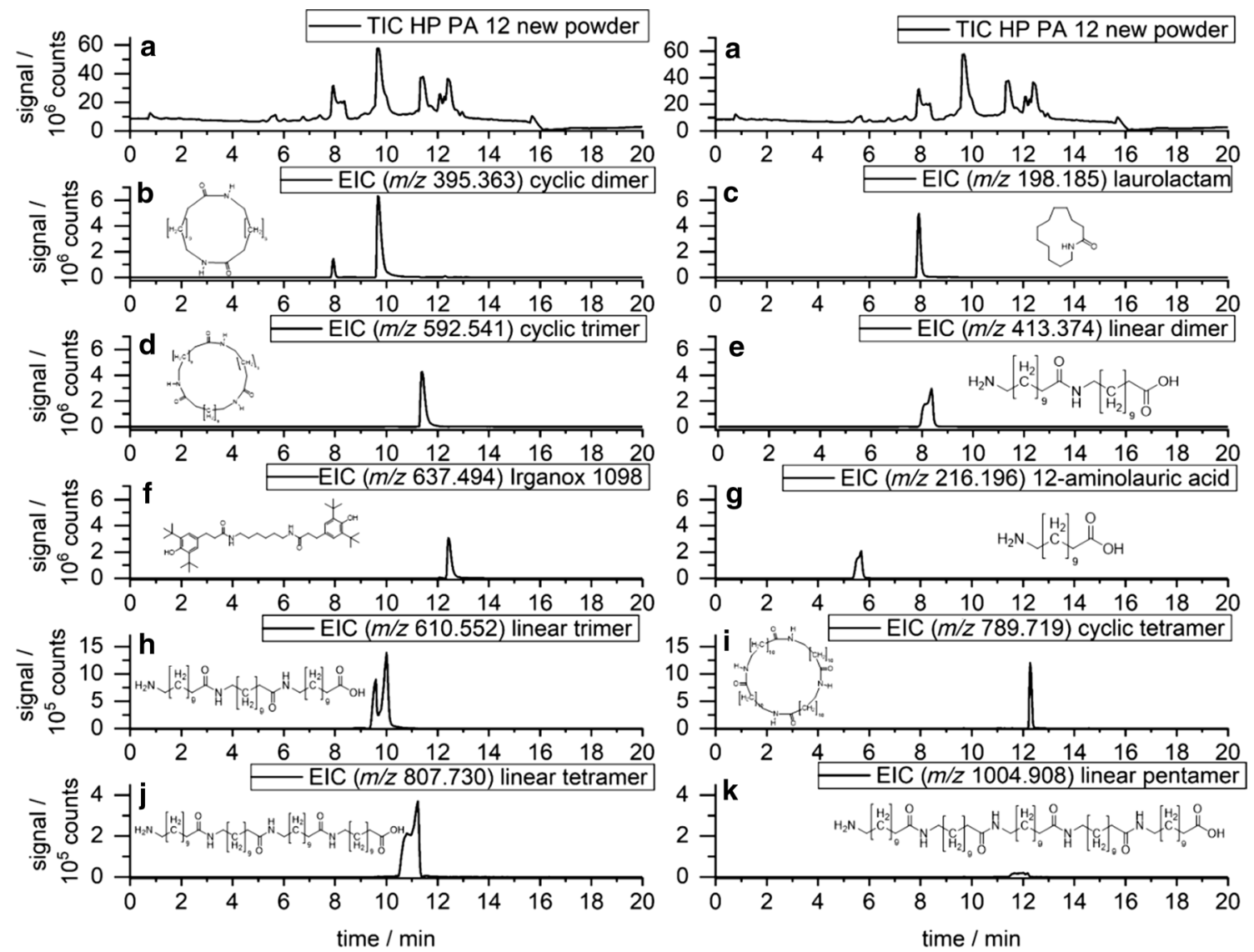

Fig. 8 a TIC of a methanol extract of new PA 12 powder from HP. The EIC traces of the monomers, oligomers, and the oxidation stabilizer are depicted: b cyclic dimer $(\mathrm{m} / \mathrm{z}, 395.363)$; c laurolactam $(\mathrm{m} / \mathrm{z}$ 198.185); d cyclic trimer $(\mathrm{m} / \mathrm{z}$ 592.541); e linear dimer $(\mathrm{m} / \mathrm{z}$ 413.374); f Irganox $1098(\mathrm{~m} / \mathrm{z}$ 637.494); g 12-aminolauric

acid $(\mathrm{m} / \mathrm{z}, 216.196)$; h linear trimer $(\mathrm{m} / \mathrm{z}, 610.552) ; \mathbf{i}$ cyclic tetramer $(\mathrm{m} / \mathrm{z}$ 789.719); j linear tetramer $(\mathrm{m} / \mathrm{z}$ 807.730); k linear pentamer $(\mathrm{m} / \mathrm{z}$ 1004.908). The EIC traces were extracted with a mass range interval of $\pm 100 \mathrm{ppm}$

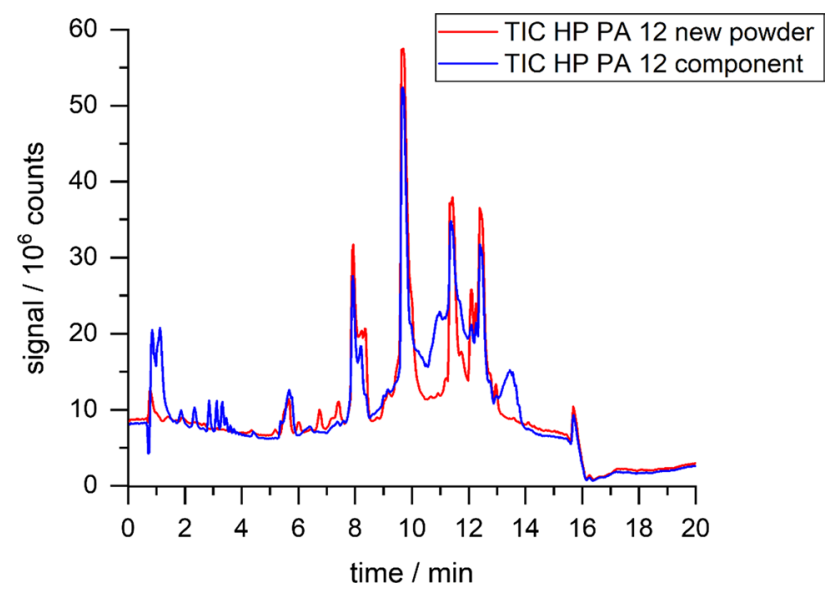

Fig. 9 TIC comparison of the methanol extract of new HP PA 12 powder (red curve) and a grinded 3D printed part fabricated from HP PA 12 powder (blue curve) (color figure online)

the peak between 13 and 14 min can only be seen in the TIC trace corresponding to the printed part. Again, the TIC trace of the detailing agent showed a peak with similar shape in the same retention time window between 13 and 14 min (compare Fig. 2a). The EIC traces of detailing agent of 2 and 3 ethoxy units (see Fig. 6a-d) depict a peak at the same retention time and again with similar curve, which indicates the peak between 13 and $14 \mathrm{~min}$ in the TIC recording of the printed part caused by compounds containing ethoxy units. In Table 1 the compounds found in the methanol extract of new HP PA 12 powder and the methanol extract of a printed part with their corresponding molecular formulas and calculated $[\mathrm{M}+\mathrm{H}]^{+}$values are summarized. Obviously, the monomers, oligomers, and the stabilizer Irganox 1098 could be detected in the new HP PA 12 powder and in the printed part. Furthermore, all substances observed in the agents were detected in the printed part except the biocide 2-methl-4-isothiazolin-3-one. This is due to the fact that the boiling point of 2-methyl-4-thiazolin-3-one $\left(93{ }^{\circ} \mathrm{C}\right.$ [28]) is much lower compared to the temperature during the energy 
Table 1 Overview of substances detected in the methanol extract of new HP PA 12 powder and the methanol extract of a printed part with their corresponding molecular formulas and calculated $[\mathrm{M}+\mathrm{H}]^{+}$results

\begin{tabular}{llcll}
\hline Compound & Molecular formula & {$[\mathrm{M}+\mathrm{H}]^{+}$} & New powder & Printed part \\
\hline Laurolactam & $\mathrm{C}_{12} \mathrm{H}_{23} \mathrm{NO}$ & 198.185 & Yes & Yes \\
12-Aminolauric acid & $\mathrm{C}_{12} \mathrm{H}_{25} \mathrm{NO}_{2}$ & 216.196 & Yes & Yes \\
Linear dimer of PA 12 & $\mathrm{C}_{24} \mathrm{H}_{48} \mathrm{~N}_{2} \mathrm{O}_{3}$ & 413.374 & Yes & Yes \\
Cyclic dimer of PA 12 & $\mathrm{C}_{24} \mathrm{H}_{46} \mathrm{~N}_{2} \mathrm{O}_{2}$ & 395.363 & Yes & Yes \\
Linear trimer of PA 12 & $\mathrm{C}_{36} \mathrm{H}_{71} \mathrm{~N}_{3} \mathrm{O}_{4}$ & 610.552 & Yes & Yes \\
Cyclic trimer of PA 12 & $\mathrm{C}_{36} \mathrm{H}_{69} \mathrm{~N}_{3} \mathrm{O}_{3}$ & 592.541 & Yes & Yes \\
Linear tetramer of PA 12 & $\mathrm{C}_{48} \mathrm{H}_{94} \mathrm{~N}_{4} \mathrm{O}_{5}$ & 807.730 & Yes & Yes \\
Cyclic tetramer of PA 12 & $\mathrm{C}_{48} \mathrm{H}_{92} \mathrm{~N}_{4} \mathrm{O}_{4}$ & 789.719 & Yes & Yes \\
Linear pentamer of PA 12 & $\mathrm{C}_{60} \mathrm{H}_{117} \mathrm{~N}_{5} \mathrm{O}_{6}$ & 1004.908 & Yes & Yes \\
Irganox 1098 & $\mathrm{C}_{40} \mathrm{H}_{64} \mathrm{~N}_{2} \mathrm{O}_{4}$ & 637.494 & Yes & Yes \\
2-Pyrrolidone & $\mathrm{C}_{4} \mathrm{H}_{7} \mathrm{NO}^{2}$ & 86.060 & No & Yes \\
Triethylene glycol & $\mathrm{C}_{6} \mathrm{H}_{14} \mathrm{O}_{4}$ & 151.097 & No & Yes \\
2-Methyl-4-isothiazolin-3-one & $\mathrm{C}_{4} \mathrm{H}_{5} \mathrm{NOS}^{2}$ & 116.017 & No & No \\
3-Benzisothiazolinone & $\mathrm{C}_{7} \mathrm{H}_{5} \mathrm{NOS}$ & 152.017 & No & Yes \\
Compounds with 2 ethoxy units & $\mathrm{C}_{4} \mathrm{H}_{8} \mathrm{O}_{2}$ & 89.060 & No & Yes \\
Compounds with 3 ethoxy units & $\mathrm{C}_{6} \mathrm{H}_{12} \mathrm{O}_{3}$ & 133.086 & No & Yes \\
\hline
\end{tabular}

input that causes the polymer melting. Consequently, the 2-methyl-4-thiazolin-3-one evaporated during the printing process. Instead, the other biocide 3-benzisothiazolinone was reported to show low volatility [28].

Furthermore, Fig. 10a, b show that the printed part also contained compounds including 2 and 3 ethoxy groups as it was the case for the agents. Since there were also signals within the range of 2-8 min retention time, it was confirmed that components of the detailing agent were detected in the methanol extract of the printed part. Thus, detailing agent was applied on the fused polymer and not solely traces of the fusing agent (compare Fig. 6a, c). Another reason might be that the detailing agent remained in the reused polymer powder due to the suggested refresh rate of $80 \%$ recycled HP PA 12 powder and 20\% new powder. Consequently, both scenarios may be responsible for compounds of the detailing agent detected in the printed part [4].

\section{Conclusion}

Fusing agent, detailing agent, new HP PA 12 powder, and a grinded 3D printed part were analytically investigated regarding their ingredients by HPLC-ESI-QTOF screening measurements. In addition, GC-FID and TGA experiments were applied for further characterization of the agents.

Both investigated agents contained 2-pyrrolidone and triethylene glycol. Furthermore, a combination of two biocides was used in the formulations in order to prevent bacterial contaminations. Moreover, substances containing two or more ethoxy units could be detected and verified by
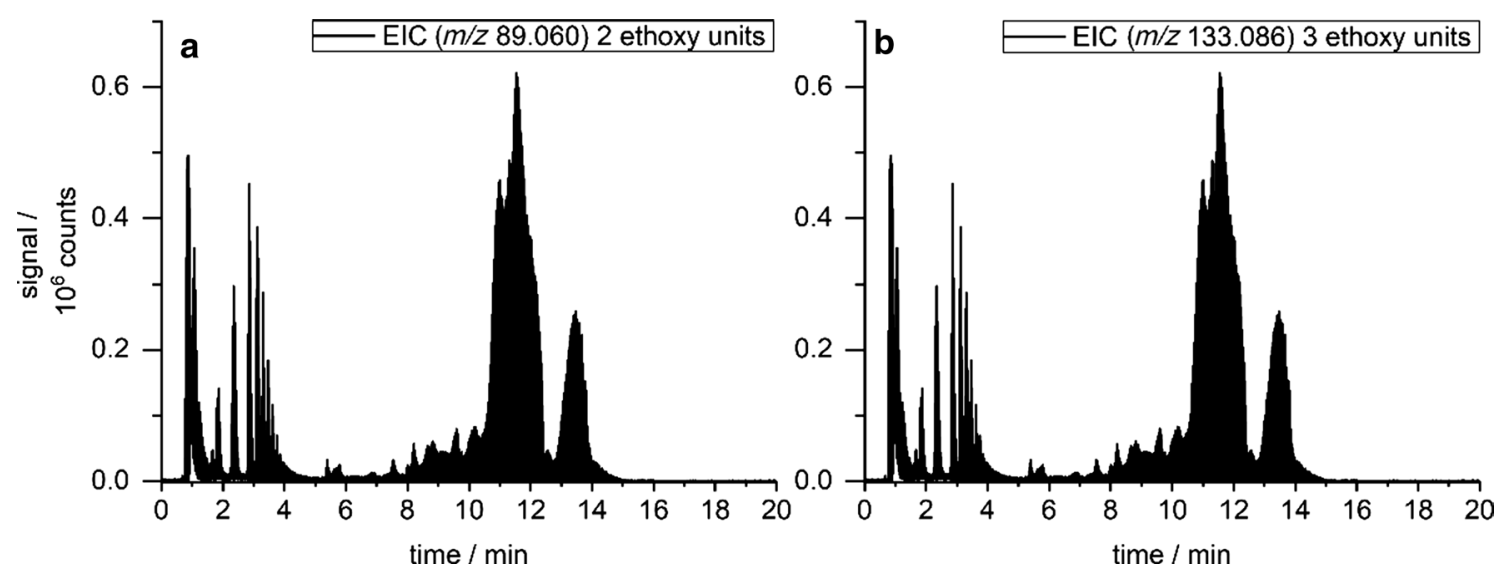

Fig. 10 EIC of a m/z 89.060 (equals 2 ethoxy units) and $\mathbf{b ~} \mathrm{m} / \mathrm{z} 133.086$ (equals 3 ethoxy units) of a methanol extract of a grinded part of HP PA 12. The chromatograms were extracted with a mass range interval of $\pm 100 \mathrm{ppm}$ 
experiments with the quadrupole applying different collision energies. Those substances could be utilized in order to adjust the viscosity of the agents, ensure homogenous agents, and the wettability of the polymer powder. However, it was not possible to determine the exact ethoxylated molecules, as those substances are applied with a homogeneous molar mass distribution. In order to guarantee the best possible processing during the printing process and part quality, the composition of the agents varied in the quantities of the detected ingredients.

In the methanol extract of the new HP PA 12 powder residues of cyclic and linear monomers and oligomers were detected. The laurolactam showed the highest intensity as it is applied as a monomer in the polymerization process. In general, higher intensities for the linear oligomers were observed compared to the cyclic ones. Moreover, the oxidation stabilizer Irganox 1098 was detected in HP PA 12 [13, 14].

All compounds detected in the agents except the 2-methyl-4-isothiazolin-3-one could be found in the methanol extract of the printed part. The 2-methyl-4-isothiazolin3 -one evaporates during the printing process as the boiling point is below the processing temperature of the multi-jet fusion process. The influence of the remaining substances of the agents observed in the printed parts has to be further investigated. Besides changes after longer periods of thermal loads, especially, the impact on mechanical properties of the printed parts needs to be examined. Using HPLC as a method for separation according to the chemical selectivity in combination with high-resolution mass spectrometry, it was possible to identify those substances based on their characteristic isotopic pattern.

High-resolution mass spectrometry in combination with collision experiments is a powerful tool for screening measurements. Useful information about soluble and ionizable compounds in unknown samples can be obtained with the chosen ion source. Furthermore, distinct fragmentation experiments and the separation according to the chemical selectivity reveal even more details regarding the detected compounds.

\section{Experimental}

\section{Reagents and chemicals}

Ethanol and methanol were of HPLC grade. Acetonitrile and non-stabilized tetrahydrofuran were of LC-MS quality. All solvents were purchased from Merck (Darmstadt, Germany) and used without further purification. Furthermore, ultrapure water $(18.2 \mathrm{M} \Omega \mathrm{cm})$ generated from a Sartorius Stedim Biotech system was used. The Karl Fischer reagent for water content determination was Hydronal ${ }^{\mathrm{TM}_{-}}$Coulomat AG-Oven from Fluka (Seelze, Germany). 2-Pyrrolidone for synthesis was purchased from Merck. The internal standard diethylene glycol monobutyl ether also used for synthesis was obtained from Merck-Schuchardt (Hohenbrunn, Germany). Triethylene glycol (99\%) was purchased from Thermo Fisher (Karlsruhe, Germany). The 3D agents (fusing and detailing agent) 3D700 were obtained from HP (Palo Alto, USA).

\section{Instrumentation and measurement conditions}

HPLC-ESI-QTOF experiments were carried out using a 1260 Infinity LC system in combination with an electrospray ionization (ESI) source and a 6530 Accurate-Mass QTOF detector from Agilent Technologies (Waldbronn, Germany). $1 \mathrm{~mm}^{3}$ of sample solution was injected into the system and was separated on a reversed-phase SB-C18, RRHD column $(1.8 \mu \mathrm{m}, 2.1 \times 150 \mathrm{~mm})$ from Agilent Technologies. Chromatographic separation was realized using gradient elution containing $0.02 \%$ formic acid in water as solvent A and acetonitrile/tetrahydrofuran $(70 / 30, \mathrm{v} / \mathrm{v})$ as solvent $\mathrm{B}$. The flow rate was set to $0.45 \mathrm{~cm}^{3} \mathrm{~min}^{-1}$. LC gradient was: $0 \mathrm{~min}$ : $95 \%$ of solvent $\mathrm{A}+5 \%$ solvent $\mathrm{B}, 1 \mathrm{~min}$ : $95 \% \mathrm{~A}+5 \% \mathrm{~B}, 15 \mathrm{~min}$ : $100 \%$ B until 20 min, followed by reconditioning of the system applying initial conditions. Column oven temperature was set to $45^{\circ} \mathrm{C}$. UV spectra were recorded in the range of 200-640 nm. The ESI source was operated in positive ion mode. Source parameters were $250{ }^{\circ} \mathrm{C}$ gas temperature, $8 \mathrm{dm}^{3} \mathrm{~min}^{-1}$ drying gas flow, 35 psi nebulizer pressure, $350{ }^{\circ} \mathrm{C}$ sheath gas temperature, and $11 \mathrm{dm}^{3} \mathrm{~min}^{-1}$ sheath gas flow $\left(\mathrm{N}_{2}\right)$. As a capillary voltage $3000 \mathrm{~V}$ were applied and a fragmentor voltage of $80 \mathrm{~V}$ was used. The skimmer voltage was set to $65 \mathrm{~V}$. MS data were received in the range of $m / z 20$ to 1500 with an acquisition rate of 2 spectra/s and an acquisition time of $500 \mathrm{~ms} / \mathrm{spectrum}$. Additionally, spectra with different collision energies of $20 \mathrm{eV}, 30 \mathrm{eV}$, and $40 \mathrm{eV}$ were recorded. Therefore, MS scans with the listed collision energies were conducted within one HPLC run. For data evaluation the Agilent MassHunter Qualitative Analysis Navigator B.08.00 and the Agilent MassHunter Qualitative Analysis Workflow B.08.00 in combination with a database research (Agilent accurate mass personal compound database and library for extractables and leachables) were applied.

Thermogravimetric measurements were performed with a NETZSCH TGA 209 F1 Libra in accordance with DIN EN ISO 11358. For this purpose, the samples were first held at $28^{\circ} \mathrm{C}$ for $15 \mathrm{~min}$ isothermally and then heated to $800{ }^{\circ} \mathrm{C}$ at a heating rate of $10 \mathrm{~K} \mathrm{~min}^{-1}$. After another isothermal phase of $10 \mathrm{~min}$, the purge gas was changed from nitrogen to oxygen and the sample was heated to $950{ }^{\circ} \mathrm{C}$ at a heating rate of $10 \mathrm{~K} \mathrm{~min}^{-1}$. Subsequently, this temperature 
Table 2 Overview of the results of the quantitative determination of water content, 2-pyrrolidone, triethylene glycol, and carbon black by Karl Fischer titration, GC-FID measurements, and thermogravimetric analysis

\begin{tabular}{llllc}
\hline Substance & Calibration type & $\begin{array}{l}\text { Recovery of } \\
\text { test sample/\% }\end{array}$ & $\begin{array}{l}\text { Amount in } \\
\text { detailing } \\
\text { agent/\% }\end{array}$ & $\begin{array}{l}\text { Amount } \\
\text { in fusing } \\
\text { agent/\% }\end{array}$ \\
\hline Water & Karl Fischer titration & - & $83 \pm 0.1$ & $65 \pm 0.4$ \\
2-Pyrrolidone & external calibration with ISTD & $97.98 \pm 0.20$ & $3.67 \pm 0.01$ & $18.74 \pm 0.02$ \\
Triethylene glycol & external calibration with ISTD & $100.24 \pm 0.02$ & $11.08 \pm 0.03$ & $8.36 \pm 0.02$ \\
Carbon black & TGA & - & 0 & $5.2 \pm 0.1$ \\
\hline
\end{tabular}

Standard deviation calculated on number of measurements ( $n=2$ for Karl Fischer titration, $n=3$ for all other determinations) was also maintained isothermal for $10 \mathrm{~min}$. The purge gas flow rate was $25 \mathrm{~cm}^{3} \mathrm{~min}^{-1}$ during the entire measurement.

The coulometric determination of water content of the agents was achieved by Karl Fischer titration using the 774 Oven Sample Processor from Metrohm (Herisau, Switzerland) according DIN EN ISO 12937.

Quantitative analyses for triethylene glycol and 2-pyrrolidone were performed using a GC-FID 7890A system (Agilent Technologies). The injector temperature was set to $280^{\circ} \mathrm{C}$. Injection volume was $1 \mathrm{~mm}^{3}$ in split mode (25:1). Helium was used as a carrier gas at a constant flow rate of $1.688 \mathrm{~cm}^{3} \mathrm{~min}^{-1}$. Chromatographic separation was carried out on a HP-5MS 5\% phenyl methyl polysiloxane $(30 \mathrm{~m} \times$ $250 \mu \mathrm{m} \times 0.25 \mu \mathrm{m})$ capillary column from Agilent Technologies. The oven temperature was set to $40{ }^{\circ} \mathrm{C}$ for 4 min followed by a temperature gradient up to $300{ }^{\circ} \mathrm{C}$ at a rate of $10{ }^{\circ} \mathrm{C} \mathrm{min}-1$. The temperature was held for $10 \mathrm{~min}$. Total analysis time was $40 \mathrm{~min}$. FID parameters were $320{ }^{\circ} \mathrm{C}$ heater temperature, $30 \mathrm{~cm}^{3} \mathrm{~min}^{-1} \mathrm{H}_{2}$ flow, $400 \mathrm{~cm}^{3} \mathrm{~min}^{-1}$ air flow, and $25 \mathrm{~cm}^{3} \mathrm{~min}^{-1}$ makeup gas flow.

\section{Sample preparation for HPLC-ESI-QTOF investigations}

A complete cross-section of the 3D printed part was grinded using the CryoMill from Retsch with a defined grinding process: 5 min precooling at $5 \mathrm{~Hz}$, followed by 3 cycles of $2 \mathrm{~min}$ grinding at $30 \mathrm{~Hz}$ with 1 min cooling time between each cycle. The grinded material was stored in the desiccator for at least one night before further preparation. $250 \mathrm{mg}$ of powder samples and agents were dissolved in $5 \mathrm{~cm}^{3}$ methanol and stored in the ultrasonic bath for 10-15 min, respectively. Fusing agent and powder samples were filtrated using a MS syringe filter $(0.2 \mu \mathrm{m}$ WWPTFE) from Acrodise (Westborough, USA).

\section{Sample preparation for GC-FID measurements}

For GC-FID measurements, standard stock solutions of $100 \mathrm{mg} \mathrm{dm}^{-3}$ of reference materials and the internal standard were prepared. Solutions from $1 \mathrm{mg} \mathrm{dm}^{-3}$ up to $10 \mathrm{mg} \mathrm{dm}^{-3}$ for calibration were prepared by diluting the stock solution.
Fusing agent samples were filtrated with a MS syringe filter (0.2 $\mu \mathrm{m}$ WWPTFE) from Acrodise (Westborough, USA).

\section{Sample preparation for TGA measurements}

For TGA measurements, the agents were conditioned at room temperature until they reached mass consistency (approx. $48 \mathrm{~h}$ ). For this purpose, the samples were weighed to $2 \mathrm{~g}$ and stored in an open petri dish. Subsequently, samples were weighed in an $85 \mathrm{~mm}^{3} \mathrm{Al}_{2} \mathrm{O}_{3}$ crucible to $10.5 \pm 0.5 \mathrm{mg}$.

\section{Quantification of 2-pyrrolidone and triethylene glycol by GC-FID}

The amount of water in the agents was determined by Karl Fischer titration. 2-Pyrrolidone and triethylene glycol were quantified by GC-FID measurements. All the results are summarized in Table 2. For quantitative determination of 2-pyrrolidone and triethylene glycol in the agents GC was chosen since the substances can be transferred to the gas phase quite easily. External calibration was conducted with internal standard for 2-pyrrolidone and triethylene glycol. As an internal standard diethylene glycol monobutyl ether was used. All calibration curves showed a strictly linear behavior. Quantification was confirmed by calculating the recovery of the test sample. A recovery of $100.2 \%$ was achieved for triethylene glycol. The detailing agent contained $11.1 \%$ triethylene glycol and $3.7 \%$ of 2-pyrrolidone. The fusing agent contained $18.7 \%$ of 2 -pyrrolidone and $8.4 \%$ of triethylene glycol.

\section{Quantification of carbon black by TGA}

The carbon black content in both agents was quantified using TGA. The conditioning of the samples resulted in a preliminary mass loss of $82.2 \%$ for the detailing agent and $61.5 \%$ for the fusing agent. No carbon black content could be determined for the detailing agent from the subsequent thermogravimetric measurements. In the case of the fusing agent, a relative carbon black content of $5.2 \%$ was obtained. 
Acknowledgements Open Access funding provided by Projekt DEAL. We are grateful to BMW AG for funding analytical equipment and financial support. Many thanks go to Gabriele Fruhmann (BMW AG, Munich) for inspiring discussions and Julius Riedelbauch (BMW AG, Munich) for providing various samples.

Open Access This article is licensed under a Creative Commons Attribution 4.0 International License, which permits use, sharing, adaptation, distribution and reproduction in any medium or format, as long as you give appropriate credit to the original author(s) and the source, provide a link to the Creative Commons licence, and indicate if changes were made. The images or other third party material in this article are included in the article's Creative Commons licence, unless indicated otherwise in a credit line to the material. If material is not included in the article's Creative Commons licence and your intended use is not permitted by statutory regulation or exceeds the permitted use, you will need to obtain permission directly from the copyright holder. To view a copy of this licence, visit http://creativecommons.org/licenses/by/4.0/.

\section{References}

1. Yuan S, Shen F, Chua CK, Zhou K (2019) Prog Polym Sci 91:141

2. Sillani F, Kleijnen RG, Vetterli M, Schmid M, Wegener K (2019) Addit Manuf 27:32

3. Ligon SC, Liska R, Stampfl J, Gurr M, Mülhaupt R (2017) Chem Rev 117:10212

4. Riedelbauch J, Rietzel D, Witt G (2019) Addit Manuf 27:259

5. Morales-Planas S, Minguella-Canela J, Lluma-Fuentes J, Travieso-Rodriguez JA, García-Granada AA (2018) Materials $11: 1472$

6. O'Connor HJ, Dickson AN, Dowling DP (2018) Addit Manuf $22: 381$

7. Aharoni SM (1997) n-Nylons: their synthesis, structure and Properties. Wiley, New York

8. Forsström D, Terselius B (2000) Polym Degrad Stab 67:69

9. Maier RD, Schiller M (eds) (2016) Handbuch Kunststoff-additive, 4th edn. Hanser, Munich

10. Ehrenstein GW, Pongratz S (2007) Beständigkeit von Kunststoffen, vol 1. Hanser, Munich

11. Janssen K, Gijsman P, Tummers D (1995) Polym Degrad Stab 49:127

12. Barret J, Gijsman P, Swagten J, Lange RFM (2002) Polym Degrad Stab 76:441
13. Okamba-Diogo O, Richaud E, Verdu J, Fernagut F, Guilment J, Pery F, Fayolle B (2016) Polym Test 52:63

14. Fish RB, Brun Y (2004) High flow, toughened, weatherable polyamide compositions containing a blend of stabilizers. US Patent 20050113532, May 26, 2005; (2005) Chem Abstr 142:482857

15. Krajník V, Božek P, Kondelíková J, Králíček J (1982) J Chromatogr A 250:138

16. Mengerink Y, van der Wal S, Claessens HA, Cramers CA (2000) J Chromatogr A 871:259

17. Mori S, Furusawa M, Takeuchi T (1970) Anal Chem 42:661

18. Feldmann VR, Feinauer R (1973) Angew Makromol Chem 34:9

19. Väisänen AJK, Hyttinen M, Ylönen S, Alonen L (2019) J Occup Environ Hyg 16:258

20. Weast RC (ed) (1977) Handbook of chemistry and physics, 58th edn. CRC Press Inc, Cleveland

21. Forkner MW, Robson JH, Snellings WM, Martin AE, Murphy FH, Parsons TE (2004) Glycols. In: Ley C (ed) Kirk-Othmer Encyclopedia of chemical technology. Wiley. https://doi. org/10.1002/0471238961.0520082506151811.a01.pub2

22. Emamjomeh A, Prasad KA, Novick MA, Fung EM (2016) Detailing Agent for Three-Dimensional (3D) Printing. WO Patent 2016171724, Oct 27, 2016; (2016) Chem Abstr 165:547962

23. Mele M, Campana G, Monti GL (2019) Addit Manuf 30:100879

24. Uhr H (2009) Stabilization of isothiazolinones using copper (II) ions and biocidal use for preservation of technical materials. EP Patent 2272348, Jan 12, 2011; (2011) Chem Abstr 154:126655

25. HP Deutschland GmbH (2020) SDS V1Q61Series: Detailing Agent. https://h22235.www2.hp.com/hpinfo/globalcitizenship/ environment/productdata/Countries/de/3d_v1q61series_de_eng_ v37.pdf. Accessed 28 Jan 2020

26. HP Deutschland GmbH (2020) SDS V1Q60Series: Fusing Agent. https://h22235.www2.hp.com/hpinfo/globalcitizenship/envir onment/productdata/Countries/de/3d_v1q60series_de_eng_v47. pdf. Accessed 28 Jan 2020

27. Dong W, Gijsman P (2010) Polym Degrad Stab 95:955

28. Wypych A, Wypych G (2015) Databook of biocides. Elsevier Science, Toronto

Publisher's Note Springer Nature remains neutral with regard to jurisdictional claims in published maps and institutional affiliations. 